\title{
The Effect of Colesevelam Treatment on Bile Acid and Lipid Metabolism and Glycemic Control in Healthy Men
}

\author{
T. BLAHOVÁ ${ }^{1}$, L. PETERKOVÁ ${ }^{1}$, M. LENÍČEK ${ }^{2}$, M. VLACHOVÁ ${ }^{1}$, K. ZEMÁNKOVÁ $^{1}$, \\ V. ADÁMKOVÁ ${ }^{1}$, L. VÍTEK ${ }^{2,3}, J^{\prime}$ KOVÁŔ ${ }^{1}$ \\ ${ }^{1}$ Institute for Clinical and Experimental Medicine, Prague, Czech Republic, ${ }^{2}$ Institute of Medical \\ Biochemistry and Laboratory Diagnostics, First Faculty of Medicine, Charles University, Prague, \\ Czech Republic, ${ }^{3}$ Fourth Department of Internal Medicine, First Faculty of Medicine, Charles \\ University, Prague, Czech Republic
}

Received December 14, 2015

Accepted April 19, 2016

On-line August 19, 2016

\section{Summary}

The treatment of hypercholesterolemia with bile acid (BA) sequestrants results in upregulation of $B A$ synthesis through the classical pathway initiated by cholesterol 7a-hydroxylase (CYP7A1). To characterize the detailed dynamics of serum lipid and $\mathrm{BA}$ concentrations and the $\mathrm{BA}$ synthesis rate in response to treatment with $B A$ sequestrants and to determine whether the $-203 A / C$ promoter polymorphism of the CYP7A1 encoding gene (CYP7A1) affects such a response, this pilot study was carried out in healthy men ( 8 homozygous for the $-203 \mathrm{~A}$ allele and 8 homozygous for the $-203 C$ allele of CYP7A1). The subjects were treated for 28 days with colesevelam and blood was drawn for analysis before and on days 1, 3, 7, 14 and 28 of treatment. The response of lipids, BA, fibroblast growth factor-19 (FGF19) and 7a-hydroxy-4-cholesten-3-one (C4) to colesevelam did not differ between carriers of $-203 \mathrm{~A}$ and $-203 \mathrm{C}$ alleles; their data were then aggregated for further analysis. Colesevelam treatment caused immediate suppression of FGF19 concentration and a fivefold increase in CYP7A1 activity, as assessed from C4 concentration, followed by a $17 \%$ decrease in LDL-cholesterol. Although total plasma BA concentrations were not affected, the ratio of cholic acid/total BA rose from $0.25 \pm 0.10$ to $0.44 \pm 0.16$ during treatment at the expense of decreases in chenodeoxycholic and deoxycholic acid.

\section{Key words}

Bile acid • Bile acid sequestrant • Cholesterol 7a-hydroxylase • LDL-cholesterol • Genetics

\section{Corresponding author}

J. Kovář, Institute for Clinical and Experimental Medicine, Laboratory for Atherosclerosis Research, Vídeňská 1958/9, 14021 Prague 4, Czech Republic. E-mail: jan.kovar@ikem.cz

\section{Introduction}

Bile acid (BA) sequestrants were originally recognized as the first drugs to efficiently decrease cholesterolemia and diminish the risk of cardiovascular disease (LRC-CPPT 1984a,b). However, due to their low efficiency and limited patient compliance, they were replaced by more potent statins. Interest in their use was revived after the arrival of new sequestrants (colestipol, colesevelam) that were better tolerated by patients and, more importantly, after they were demonstrated to have a positive effect on glycemic control (Zieve et al. 2007).

The direct effect of sequestrants on BA uptake diminishes their enterohepatic recirculation, resulting in upregulation of BA de novo synthesis from cholesterol in the liver. The consumption of intracellular cholesterol induces an increase in LDL receptor activity and, subsequently, a drop in LDL-cholesterol concentration (Insull 2006, Couture and Lamarche 2013).

Cholesterol 7 $\alpha$-hydroxylase (CYP7A1), the first and key regulatory enzyme of the classical pathway of BA synthesis, plays a critical role in this process. Its expression is controlled by two main regulatory 
feedback mechanisms (Chiang 2009). First, BA returning to the liver bind to the hepatic farnesoid $\mathrm{X}$ receptor (FXR) and induce expression of the small heterodimer partner (SHP). SHP then inhibits expression of the cholesterol $7 \alpha$-hydroxylase gene (CYP7A1). Second, BA, after binding to FXR in enterocytes, induce the intestinal expression of fibroblast growth factor 19 (FGF19), which is then secreted into systemic circulation. FGF19 interacts with FGF receptor 4 (FGFR4) on hepatocytes and inhibits expression of CYP7A1 via the MAPK/ERK1/2 signaling pathway.

Interestingly, several functional polymorphisms have been identified in the promoter region of the CYP7A1 gene. One of them, the $-203 \mathrm{~A} / \mathrm{C}$ polymorphism (rs 3808607), has been shown to affect cholesterolemia (Wang et al. 1998, Couture et al. 1999) and/or cholesterolemia responsiveness to diet (Hubacek et al. 2003, Hofman et al. 2004, Kovar et al. 2004) and also modulate the effectiveness of statin therapy (Kajinami et al. 2004, Kajinami et al. 2005). It is not clear yet whether this polymorphism may also affect the response to BA sequestrant therapy in healthy men.

Increased synthesis of BA through the classical pathway initiated by CYP7A1 can also be of great importance with respect to the recently recognized role of BA as important signaling molecules involved in the regulation of lipid, glucose and energy homeostasis (Chiang 2013, Vítek and Haluzík 2016). It has been shown that BA sequestrant treatment affects the concentrations of individual BA in circulation (Brufau et al. 2010), which might have an impact on their signaling role, in particular due to marked differences in the biological activities of individual BA (Liu et al. 2014).

Therefore, in this pilot study of healthy men, we characterized in detail the dynamics of the responses of lipids, BA, FGF19 and also $7 \alpha$-hydroxy-4-cholesten3-one (C4) (a plasma marker of CYP7A1 activity; Axelson et al. 1991, Sauter et al. 1996) to treatment with colesevelam, a novel bile acid sequestrant. To determine whether such a response is affected by the promoter polymorphism of the CYP7A1 gene, the study was carried out in subjects homozygous either for the -203A or -203C allele of CYP7A1. We also analyzed the effect of treatment on parameters related to glycemic control and thyroid hormone metabolism, which can also be affected by bile acid sequestrants (Zieve et al. 2007, Ockenga et al. 2012).
Table 1. Baseline characteristics of subjects separated according to the CYP7A1 genotype.

\begin{tabular}{|c|c|c|c|}
\hline & $\mathbf{A A}$ & $\mathbf{C C}$ & p value \\
\hline$n$ & 8 & 8 & \\
\hline Age [years] & $40.7 \pm 9.0$ & $43.2 \pm 13.8$ & 0.677 \\
\hline$B M I\left[\mathrm{~kg} / \mathrm{m}^{2}\right]$ & $25.4 \pm 2.1$ & $24.0 \pm 2.7$ & 0.258 \\
\hline Cholesterol[mmol/l] & $5.64 \pm 0.80$ & $4.94 \pm 1.46$ & 0.259 \\
\hline$L D L-C[\mathrm{mmol} / \mathrm{ll}]$ & $3.77 \pm 0.63$ & $2.97 \pm 1.17$ & 0.118 \\
\hline$H D L-C[\mathrm{mmol} / \mathrm{l}]$ & $1.32 \pm 0.31$ & $1.41 \pm 0.20$ & 0.490 \\
\hline$T G[\mathrm{mmol} / \mathrm{ll}]$ & $1.23 \pm 0.30$ & $1.24 \pm 0.67$ & 0.955 \\
\hline Glucose [mmol/l] & $5.50 \pm 0.43$ & $5.38 \pm 0.37$ & 0.547 \\
\hline$C 4[\mu g / l]$ & $29.4 \pm 21.9$ & $12.6 \pm 7.8$ & 0.115 \\
\hline$F G F-19[n g / l]$ & $144 \pm 90$ & $187 \pm 142$ & 0.573 \\
\hline$B A[\mu \mathrm{mol} / l]$ & $\begin{array}{c}1.60 \\
(0.92-3.25)\end{array}$ & $\begin{array}{c}2.38 \\
(1.07-3.43)\end{array}$ & 0.721 \\
\hline$C A[\mu \mathrm{mol} / l]$ & $\begin{array}{c}0.27 \\
(0.14-0.78)\end{array}$ & $\begin{array}{c}0.53 \\
(0.32-1.29)\end{array}$ & 0.279 \\
\hline$C D C A[\mu \mathrm{mol} / l]$ & $\begin{array}{c}0.53 \\
(0.42-1.13)\end{array}$ & $\begin{array}{c}0.78 \\
(0.51-1.52)\end{array}$ & 0.599 \\
\hline DCA [ & $\begin{array}{c}0.85 \\
(0.36-1.20)\end{array}$ & $\begin{array}{c}0.30 \\
(0.20-0.66)\end{array}$ & 0.270 \\
\hline
\end{tabular}

Data are mean \pm SD or median (IQ range), depending on the data normality. There were no significant differences between groups. Differences between groups were evaluated using the unpaired t-test or the Mann-Whitney rank-sum test, where appropriate. AA, CC - homozygous carriers of the $-203 \mathrm{~A}$ and $-203 C$ alleles of the CYP7A1 gene, BMI - body mass index, LDL-C - low-density lipoprotein cholesterol, HDL-C - high-density lipoprotein cholesterol, TG - triglyceride, C4 - 7a-hydroxy-4cholesten-3-one, FGF19 - fibroblast growth factor-19, BA - bile acids, CA - cholic acid, CDCA - chenodeoxycholic acid, DCA deoxycholic acid, LCA - lithocholic acid, UDCA - ursodeoxycholic acid. Lithocholic and ursodeoxycholic acid concentrations are not shown because they were under the limit of detection in most subjects.

\section{Methods}

\section{Subjects and study design}

Sixteen healthy men (eight homozygous for the A allele and eight homozygous for the $\mathrm{C}$ allele) were selected from the employees of both participating institutions and from a number of healthy subjects who participated in a preventive medical program (Vítek et al. 2013). The exclusion criteria included triglyceride (TG) concentration higher than $2.0 \mathrm{mmol} / \mathrm{l}$ and abnormal liver function tests (AST $>0.58 \mu \mathrm{kat} / \mathrm{l}, \mathrm{ALT}>0.75 \mu \mathrm{kat} / \mathrm{l})$. Both groups did not significantly differ in age, BMI or lipid concentration upon entering the study (Table 1).

The subjects were administered colesevelam 
(Cholestagel $\AA$, Genzyme Europe B.V., the Netherlands) for 4 weeks. Colesevelam ( $3.75 \mathrm{~g} /$ day) was given in one daily dose taken with a meal except of one subject who preferred to take it in two doses due to discomfort when taking six large tablets at once. Blood for determination of biochemical parameters was drawn on the first day of treatment (day 0 ) before application of the first dose of the drug and on days 1, 3, 7, 14 and 28 of treatment. Blood sampling was carried out in the morning in a fasting state at exactly the same time of a day in each of the subjects to diminish the effect of diurnal variation. The blood was collected in tubes with EDTA and immediately transferred to ice. A dipeptidyl peptidase-4 (DPP4) inhibitor was added immediately after blood samples were drawn for glucagon-like peptide 1 (GLP-1) analysis. Plasma samples were stored at $-80{ }^{\circ} \mathrm{C}$ until the analyses were performed.

The protocol of the study adhered to the Principles of the Declaration of Helsinki and was approved by the Ethics Committee of the Institute for Clinical and Experimental Medicine and Thomayer Hospital in Prague, Czech Republic. All participants gave their informed consent.

\section{Analytical methods}

The concentrations of cholesterol, HDL-cholesterol and triglyceride in plasma were measured using enzymatic kits from Roche Diagnostics (Mannheim, Germany), LDL-cholesterol was calculated based on the Friedewald formula, non-esterified fatty acids (NEFA) were determined using a kit from Wako Chemicals $\mathrm{GmbH}$ (Germany), and glucose using a kit from Erba Lachema (Brno, Czech Republic). Insulin concentrations were determined using a radioimmunometric kit from Beckman Coulter (Prague, Czech Republic). Insulin resistance was assessed using the homeostasis model assessment of insulin resistance (HOMA-IR) (Matthews et al. 1985). Thyroxine (T4), free thyroxine (fT4), triiodothyronine (T3), free triiodothyronine (fT3) and thyroid-stimulating hormone (TSH) were determined using radioimmunoassay kits (Beckman Coulter, Prague, Czech Republic). Fibroblast growth factor-19 (FGF-19) was measured using ELISA kit (R\&D Systems, Abingdon, UK) and total GLP1 and active GLP-1 (i.e. intact functional GLP-1 not subjected to the action of an endogenous DPP-4 inhibitor) also with ELISA kits (EMD Millipore, St Charles, USA). Serum levels of bile acids were determined as described previously (Setchell and Lawson 1989, Haluzikova et al. 2013). The levels of $7 \alpha$-hydroxy-4-cholesten-3-one (C4) were determined by HPLC and mass spectroscopy. Briefly,
$100 \mu \mathrm{l}$ of serum and $2 \mathrm{ng}$ of the internal standard (7 $\alpha$-hydroxy-4-cholesten-3-one d7, Santa Cruz Biotechnology, USA) in $40 \mu \mathrm{l}$ of methanol were mixed and extracted as previously reported (Lenicek et al. 2008a). The purified sample was dissolved in $50 \mu \mathrm{l}$ of $75 \%$ methanol, $15 \mu \mathrm{l}$ were injected on HPLC system (Dionex Ultimate 3000, Dionex Softron GmbH, Germany) equipped with a Hypersil GOLD column $(150 \times 2.1 \mathrm{~mm}$, $3 \mu \mathrm{m}$, Thermo Scientific, USA) and SecurityGuard column (Phenomenex, USA). The sample was separated by methanol (LC-MS grade, Biosolve BV, the Netherlands), water and ammonium acetate (LC-MS grade, SigmaAldrich, USA) at a flow rate of $0.3 \mathrm{ml} / \mathrm{min}\left(40^{\circ} \mathrm{C}\right)$. While the ammonium acetate concentration was kept at $0.1 \%$ $(\mathrm{w} / \mathrm{v})$ at all times, methanol concentrations $(\mathrm{v} / \mathrm{v})$ were as follows: $1-8 \mathrm{~min} 82-90 \%$; 8-10 $\mathrm{min} 90 \%$; 10-12 $\mathrm{min}$ $99 \%$; $12-17 \min 82 \%$.

A triple quadrupole mass spectrometer (TSQ Quantum Access Max with an H-ESI II probe, Thermo Fisher Scientific, Inc., USA) operating in SIM mode was used as the detector. Transitions used for monitoring $\mathrm{C} 4$ and the internal standard were: $\mathrm{m} / \mathrm{z} \quad 401.4 \rightarrow 177.3$, $401.4 \rightarrow 383.6$ and $408.4 \rightarrow 184.3, \quad 408.4 \rightarrow 390.6$, respectively.

\section{Genotyping}

Determination of the $-203 \mathrm{~A} / \mathrm{C}$ genotype of CYP7A1 was carried out as described earlier (Lenicek et al. 2008b).

\section{Statistics}

The effect of the CYP7A1 genotype on changes to all parameters during the study was evaluated using ANOVA for repeated measures with one grouping factor (genotype). Data for analysis were logarithmically transformed where necessary. ANOVA for repeated measures or its non-parametric variant (the Friedman test) were then used for analysis of the pooled data from all subjects. Corresponding post-hoc tests were carried out where significant differences were detected using ANOVA or the Friedman test (GraphPad InStat 3.00, GraphPad Software, San Diego, CA, USA).

\section{Results}

The treatment with colesevelam was well tolerated by all the subjects in the study and resulted in expected decrease of cholesterol and LDL-C in all of them (Table 2). 
Table 2. The response of lipids, lipoproteins and bile acids to treatment with colesevelam.

\begin{tabular}{|c|c|c|c|c|c|c|c|}
\hline & \multicolumn{6}{|c|}{ Day } & \multirow[t]{2}{*}{ ANOVA } \\
\hline & $\mathbf{0}$ & 1 & 3 & 7 & 14 & 28 & \\
\hline $\begin{array}{l}\text { Cholesterol } \\
{[\mathrm{mmol} / \mathrm{l}]}\end{array}$ & $5.29 \pm 1.19$ & $5.33 \pm 1.13$ & $5.00 \pm 1.02$ & $4.88 \pm 1.0^{* *}$ & $4.83 \pm 0.86^{* *}$ & $4.85 \pm 0.91^{* *}$ & $<0.001$ \\
\hline $\begin{array}{l}L D L-C \\
{[\mathrm{mmol} / \mathrm{ll}]}\end{array}$ & $3.37 \pm 1.00$ & $3.43 \pm 1.00$ & $2.92 \pm 0.76^{* *}$ & $2.81 \pm 0.83^{* *}$ & $2.74 \pm 0.60^{* *}$ & $2.80 \pm 0.85^{* *}$ & $<0.001$ \\
\hline $\begin{array}{l}H D L-C \\
{[\mathrm{mmol} / \mathrm{ll}]}\end{array}$ & $1.36 \pm 0.25$ & $1.34 \pm 0.26$ & $1.30 \pm 0.29$ & $1.38 \pm 0.27$ & $1.39 \pm 0.30$ & $1.43 \pm 0.30$ & 0.098 \\
\hline $\begin{array}{l}T G \\
{[\mathrm{mmol} / \mathrm{ll}]}\end{array}$ & $1.23 \pm 0.50$ & $1.22 \pm 0.46$ & $1.72 \pm 1.22$ & $1.51 \pm 0.80$ & $1.53 \pm 1.11$ & $1.36 \pm 0.81$ & 0.190 \\
\hline $\begin{array}{l}B A \\
{[\mu \mathrm{mol} / \mathrm{l}]}\end{array}$ & $\begin{array}{c}1.91 \\
(0.97-4.08)\end{array}$ & $\begin{array}{c}1.56 \\
(0.80-4.27)\end{array}$ & $\begin{array}{c}1.25 \\
(0.81-2.17)\end{array}$ & $\begin{array}{c}1.49 \\
(0.95-2.06)\end{array}$ & $\begin{array}{c}1.84 \\
(0.98-5.45)\end{array}$ & $\begin{array}{c}1.40 \\
(1.05-1.82)\end{array}$ & $0.771^{\S}$ \\
\hline $\begin{array}{l}\text { CA } \\
{[\mu \mathrm{mol} / \mathrm{l}]}\end{array}$ & $\begin{array}{c}0.38 \\
(0.18-1.33)\end{array}$ & $\begin{array}{c}0.45 \\
(0.20-1.54)\end{array}$ & $\begin{array}{c}0.42 \\
(0.25-1.15)\end{array}$ & $\begin{array}{c}0.54 \\
(0.32-1.06)\end{array}$ & $\begin{array}{c}0.67 \\
(0.40-1.37)\end{array}$ & $\begin{array}{c}0.45 \\
(0.42-0.93)\end{array}$ & $0.155^{\S}$ \\
\hline $\begin{array}{l}\text { CDCA } \\
{[\mu \mathrm{mol} / l]}\end{array}$ & $\begin{array}{c}0.65 \\
(0.39-1.25)\end{array}$ & $\begin{array}{c}0.49 \\
(0.32-0.98)\end{array}$ & $\begin{array}{c}0.43 \\
(0.23-0.88)\end{array}$ & $\begin{array}{c}0.42 \\
(0.38-0.66)\end{array}$ & $\begin{array}{c}0.58 \\
(0.32-0.71)\end{array}$ & $\begin{array}{c}0.46 \\
(0.36-0.72)\end{array}$ & $0.654^{\S}$ \\
\hline $\begin{array}{l}D C A \\
{[\mu \mathrm{mol} / l]}\end{array}$ & $\begin{array}{c}0.44 \\
(0.24-1.15)\end{array}$ & $\begin{array}{c}0.34 \\
(0.16-0.83)\end{array}$ & $\begin{array}{c}0.17^{* *} \\
(0.12-0.33)\end{array}$ & $\begin{array}{c}0.24 * * \\
(0.18-0.37)\end{array}$ & $\begin{array}{c}0.27 \\
(0.16-0.55)\end{array}$ & $\begin{array}{c}0.26 \\
(0.17-0.41)\end{array}$ & $0.003^{\S}$ \\
\hline
\end{tabular}

Data are mean \pm SD or median (IQ range). ANOVA - significance calculated by ANOVA for repeated measures or using the Friedman test $^{\S}$. ** $\mathrm{p}<0.01$ vs. day 0 . LDL-C - low-density lipoprotein cholesterol, HDL-C - high-density lipoprotein cholesterol, TG - triglyceride, BA - bile acids, CA - cholic acid, CDCA - chenodeoxycholic acid, DCA - deoxycholic acid. Lithocholic and ursodeoxycholic acid concentrations are not shown because they were under the limit of detection in most subjects.

The effect of the -203A/C polymorphism on CYP7A1 activity and the response of cholesterol to treatment with colesevelam

There were no significant differences between homozygous carriers of $-203 \mathrm{~A}$ and $-203 \mathrm{C}$ alleles for all parameters measured in the study at baseline (day 0 ) (Table 1). Importantly, when the ANOVA for repeated measures with one grouping factor (genotype) was used to analyze the response of lipids, C4, FGF-19, BA and parameters related to glucose control and thyroidal function to colesevelam therapy, no significant differences between carriers of -203A and -203C alleles were detected (data not shown). Interestingly, the concentration of $\mathrm{C} 4$ was more than twice as high, albeit not significantly, in homozygous A allele carriers as in C allele carriers on day 0 of the study $(29.4 \pm 21.9$ vs. $12.6 \pm 7.8 \mu \mathrm{g} / \mathrm{l}, \mathrm{p}=0.115$ ). However, the response of $\mathrm{C} 4$ concentration to the therapy did not differ between -203A and $-203 \mathrm{C}$ carriers (data not shown). Therefore, all other analyses of the effect of colesevelam treatment were carried out for all sixteen subjects altogether, regardless of genotype.

\section{The effect of colesevelam treatment on lipoproteins}

Cholesterolemia decreased by $8 \%$ after a week of treatment and remained stable till the end of the study (Table 2). This decrease was caused by an approximate $17 \%$ decrease in LDL-cholesterol, which had already become significant after 3 days on colesevelam (Table 2, Fig. 1). Neither HDL-C nor TG concentration was affected by the treatment. Although the mean TG concentration rose only non-significantly during colesevelam therapy, transient elevations in TG concentration were observed in 5 subjects on six occasions (triglyceridemia was more than twice as high when compared to day 0 ).

The effect of colesevelam treatment on regulation of $B A$ synthesis and concentration

Concentration of FGF19 dropped to approximately one third of the baseline value as early as on the first day of therapy and remained at this level until the end of the study (Fig. 1). Simultaneously, the concentration of $\mathrm{C} 4$ - a plasma marker of CYP7A1 activity - increased more than twofold on day 1 and progressed to fivefold higher levels on day 3 , but did not 
then change further (Fig. 1).

Treatment with colesevelam had no significant effect either on total concentrations of plasma BA (Table 2, Fig. 1) or individual BA, except for concentration of DCA, which was markedly suppressed after 3 and 7 days of therapy (Table 2). However, the ratio of $\mathrm{CA} /$ total $\mathrm{BA}$ rose from $0.25 \pm 0.10$ at the beginning of the study to $0.44 \pm 0.16$ at the end and the ratio of $\mathrm{CDCA} /$ total $\mathrm{BA}$ dropped from $0.40 \pm 0.13$ to $0.32 \pm 0.08$ (Fig. 1). Moreover, the share of the sum of both primary BA, CA and CDCA from the total BA concentration rose from $0.65 \pm 0.17$ to $0.76 \pm 0.14$ (Fig. 1).
LDL-C

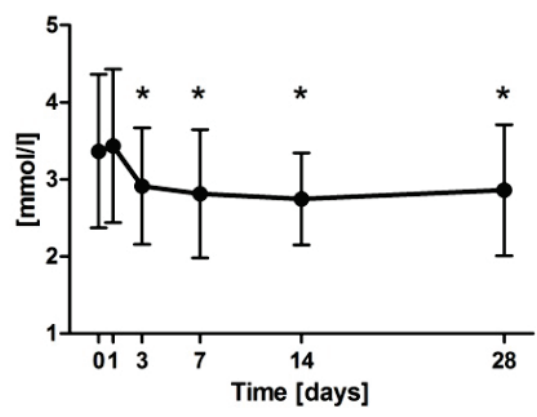

C4

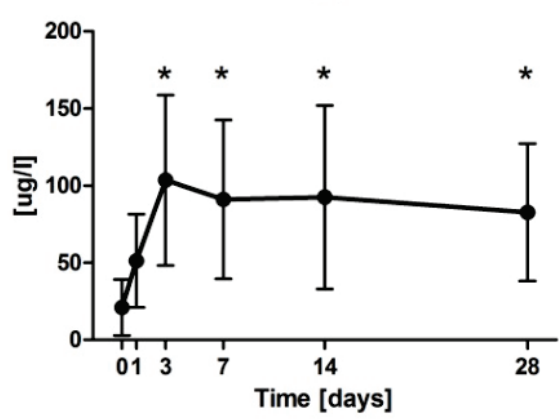

CA/BA

CDCA/BA

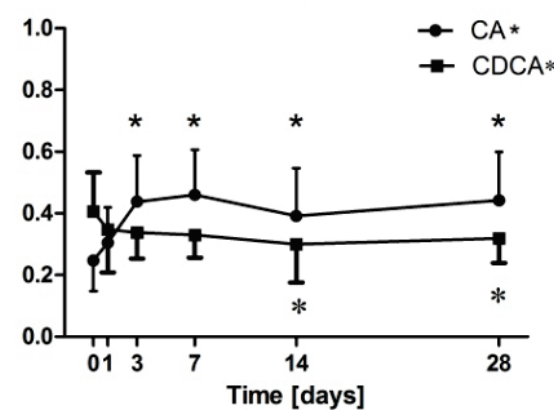

BA

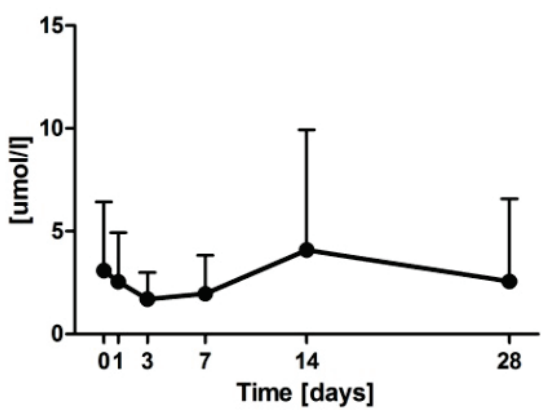

FGF-19

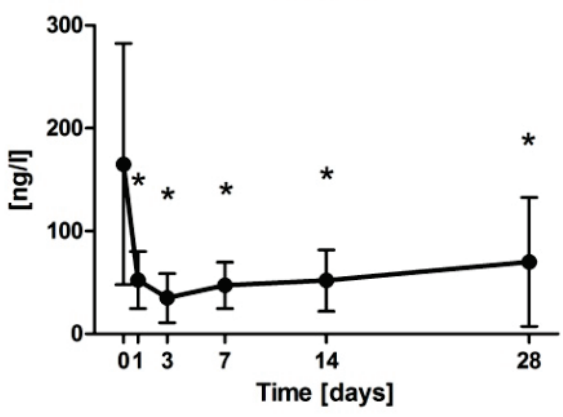

CA+CDCA/BA

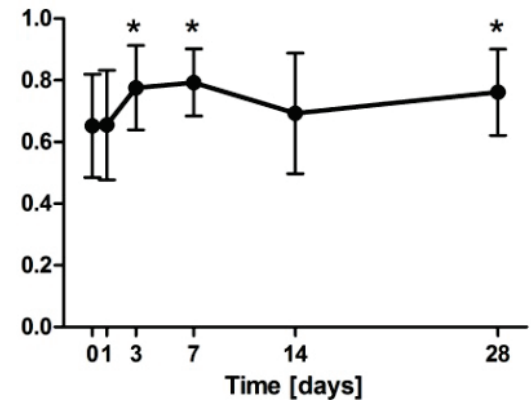

Fig. 1. The response of selected parameters of lipid and BA metabolism to treatment with colesevelam. Data are mean \pm SD. LDL-C - low density lipoproteincholesterol, BA - bile acids, C4 - 7a-hydroxy-4-cholesten-3one, FGF19 - fibroblast growth factor-19, CA - cholic acid, CDCA chenodeoxycholic acid, DCA deoxycholic acid. * $\mathrm{p}<0.05$ vs. baseline.

The effect of treatment on parameters related to glycemic control and thyroidal function

A transient $5 \%$ decrease in glycemia was observed on day 3 of the study (Table 3 ). However, treatment with colesevelam had no significant effect on insulin or on total and active GLP-1 concentrations in our group of healthy men. Also, HOMA-IR was not affected by the treatment.
Treatment with colesevelam resulted in a transient increase in TSH concentration, peaking on day 7 (Table 3). Neither total nor free thyroxin (T4) concentrations were affected by the colesevelam treatment, although both total and free triiodthyronine (T3) concentrations tended to be somewhat higher at the end of the study. The ratio of T3/T4 was approximately $10 \%$ higher at the end of the study. 
Table 3. The response of parameters of glycemic control and thyroidal function to treatment with colesevelam.

\begin{tabular}{|c|c|c|c|c|c|c|c|}
\hline & \multicolumn{6}{|c|}{ Day } & \multirow[t]{2}{*}{ ANOVA } \\
\hline & $\mathbf{0}$ & 1 & 3 & 7 & 14 & 28 & \\
\hline $\begin{array}{l}\text { Glucose } \\
\text { [mmol/l] }\end{array}$ & $5.44 \pm 0.40$ & $5.33 \pm 0.33$ & $5.16 \pm 0.32 *$ & $5.23 \pm 0.33$ & $5.22 \pm 0.39$ & $5.46 \pm 0.43$ & 0.013 \\
\hline $\begin{array}{l}\text { Insulin } \\
{[\mathrm{mIU} / \mathrm{l}]}\end{array}$ & $6.5 \pm 3.6$ & $6.2 \pm 2.2$ & $5.9 \pm 2.7$ & $5.7 \pm 3.0$ & $5.0 \pm 2.4$ & $5.4 \pm 2.7$ & 0.241 \\
\hline$H O M A-I R$ & $1.61 \pm 0.97$ & $1.48 \pm 0.57$ & $1.36 \pm 0.62$ & $1.34 \pm 0.75$ & $1.16 \pm 0.57$ & $1.32 \pm 0.70$ & 0.171 \\
\hline $\begin{array}{l}\text { Active GLP-1 } \\
\text { [pmol/l] }\end{array}$ & $2.87 \pm 0.86$ & $2.96 \pm 0.93$ & $3.10 \pm 1.10$ & $3.21 \pm 1.38$ & $2.93 \pm 0.68$ & $3.00 \pm 0.91$ & 0.981 \\
\hline $\begin{array}{l}\text { Total GLP-1 } \\
{[\mathrm{pmol} / \mathrm{l}]}\end{array}$ & $9.00 \pm 3.42$ & $8.53 \pm 4.20$ & $11.08 \pm 7.20$ & $10.72 \pm 4.83$ & $10.24 \pm 6.20$ & $10.48 \pm 7.97$ & 0.150 \\
\hline $\begin{array}{l}\text { TSH } \\
{[\mu \mathrm{mol} / \mathrm{l}]}\end{array}$ & $3.22 \pm 1.72$ & $3.00 \pm 1.36$ & $2.95 \pm 1.30$ & $3.81 \pm 1.87$ & $3.34 \pm 1.49$ & $2.83 \pm 1.25$ & 0.001 \\
\hline $\begin{array}{l}\text { T4 } \\
{[\text { nmol/l] }}\end{array}$ & $77.2 \pm 10.7$ & $77.6 \pm 14.7$ & $77.4 \pm 11.2$ & $77.4 \pm 9.7$ & $76.8 \pm 10.4$ & $75.7 \pm 10.1$ & 0.943 \\
\hline $\begin{array}{l}\text { Free T4 } \\
{[\text { pmol/l] }}\end{array}$ & $15.3 \pm 2.2$ & $15.4 \pm 2.0$ & $15.1 \pm 2.1$ & $14.9 \pm 1.9$ & $15.3 \pm 2.0$ & $15.1 \pm 2.0$ & 0.713 \\
\hline $\begin{array}{l}\text { T3 } \\
{[\mathrm{nmol} / \mathrm{l}]}\end{array}$ & $1.61 \pm 0.20$ & $1.62 \pm 0.22$ & $1.52 \pm 0.15$ & $1.57 \pm 0.23$ & $1.66 \pm 0.31$ & $1.69 \pm 0.25$ & 0.007 \\
\hline $\begin{array}{l}\text { Free T3 } \\
{[\mathrm{pmol} / \mathrm{l}]}\end{array}$ & $5.00 \pm 0.84$ & $5.00 \pm 0.72$ & $4.80 \pm 0.82$ & $4.92 \pm 0.61$ & $5.25 \pm 0.71$ & $5.09 \pm 0.64$ & 0.011 \\
\hline $1000 * T 3 / T 4$ & $20.2 \pm 2.4$ & $20.6 \pm 1.8$ & $19.8 \pm 2.2$ & $20.3 \pm 2.5$ & $22.0 \pm 3.0$ & $22.4 \pm 2.4$ & $0.004^{\S}$ \\
\hline Free T3/free T4 & $0.331 \pm 0.057$ & $0.329 \pm 0.054$ & $0.319 \pm 0.053$ & $0.334 \pm 0.047$ & $0.349 \pm 0.065$ & $0.342 \pm 0.054$ & 0.385 \\
\hline
\end{tabular}

Data are mean $\pm \mathrm{SD}$. ANOVA - significance calculated from ANOVA for repeated measures and/or from the Friedman test ${ }^{\S} * \mathrm{p}<0.01$ vs. day 0 . HOMA-IR - insulin resistance from the homeostasis model assessment, GLP-1 - glucagon-like peptide 1 , TSH - thyroidstimulating hormone, T4 - thyroxine, T3 - triiodothyronine.

\section{Discussion}

In our pilot study of healthy men, we document that treatment with colesevelam, a new generation BA sequestrant, resulted in an immediate downregulation of FGF-19 concentration followed by a severalfold increase in BA synthesis within three days and a decrease in LDL-cholesterol concentration within a week. Although plasma concentrations of total BA were not affected (presumably due to low baseline levels in the healthy individuals of the study), changes to the spectrum of individual $\mathrm{BA}$, characterized by an increase in CA and a decrease in CDCA, were observed. These changes were not affected by the promoter polymorphism of CYP7A1.

The $-203 \mathrm{~A} / \mathrm{C}$ polymorphism, which has been previously shown to affect cholesterolemia and cholesterol responsiveness to diet, did not seem to have any effect on the response of BA synthesis and plasma cholesterol to treatment with colesevelam in healthy volunteers. It can be assumed that, due to the high loss of $\mathrm{BA}$ as a result of treament with the BA sequestrant, CYP7A1 activity must have been markedly upregulated to compensate for depletion of the BA pool. The extent of such depletion should not be affected by CYP7A1 promoter polymorphism and may be the driving force in the upregulation of CYP7A1 activity. Therefore, under these conditions, the rate of BA synthesis may not have been affected by the $C Y P 7 A 1$ polymorphism.

Because there were no differences between both -203A and -203C allele homozygous carriers at all, we aggregated all subjects for all other analyses.

It is worth noting that the response of FGF-19 to the treatment was immediate - it dropped to $30 \%$ of the baseline values as early as on day 1 and did not change further (Fig. 1). The activity of CYP7A1, as assessed from $\mathrm{C} 4$ concentration, also responded very quickly - it reached its maximum on day 3 and then did not change significantly (Fig. 1). The increased consumption of 
hepatic cholesterol for BA synthesis resulted in a $13 \%$ reduction of LDL-cholesterol (Fig. 1), which fully explains the decrease of total cholesterol concentration because the HDL-C concentration was unaffected. The final reduction of $17 \%$ and $8 \%$ for LDL-C and total cholesterol, respectively, seems to be in the line with other studies (Insull 2006). Importantly, although mean triglyceridemia rose during the study, the increase was not significant. When the data were thoroughly examined, we noticed transient elevations of triglyceridemia in some subjects. It has been suggested that BA downregulate triglyceride synthesis and VLDL secretion via a pathway involving FXR, SHP and SREBP-1c (Watanabe et al. 2004). It cannot be excluded that this signaling pathway is indeed attenuated in certain subjects during colesevelam treatment because hydrophilic CA, whose proportion is lower during the treatment, is a weak agonist of FXR (Wang et al. 1999).

Importantly, colesevelam treatment did not affect total fasting BA concentrations, probably due to their overall low plasma concentrations in our healthy subjects. However, there were marked changes in the spectrum of individual BA. Due to the high variability of individual BA concentrations, the changes to individual BA concentrations did not reach statistical significance during the study, except for a transient decrease in DCA concentration. However, the ratio of $\mathrm{CA} /$ total $\mathrm{BA}$ increased 1.8 times within three days and then remained stable during the treatment. This increase took place at the expense of CDCA and DCA concentrations. Moreover, the ratio of $(\mathrm{CA}+\mathrm{CDCA}) / \mathrm{BA}$ also increased after the treatment, indicative of the higher contribution of primary BA to the total BA pool. These findings are in relatively close agreement with those of Brufau et al. (2010) who demonstrated that the BA pool becomes more hydrophilic after colesevelam treatment in both healthy and diabetic subjects. Based on our data, we can only speculate on the mechanisms behind these changes. First, the increase in the proportion of CA may be due to the higher affinity of colesevelam for more hydrophobic BA. But this seems unlikely because colesevelam was designed to bind to $\mathrm{CA}$ with higher efficiency (Insull 2006). Second, the higher proportion of CA may result from the increased activity of sterol- $12 \alpha$-hydroxylase (CYP8B1). This enzyme is responsible for CA synthesis and its expression is regulated through the action of FXR and SHP in exactly the same way as expression of the CYP7A1 gene (Goodwin et al. 2000). Third, the proportion of CA may increase because of the lower conversion to DCA in the intestine. This could provide an explanation for the transient decrease of DCA after 3 and 7 days of treatment and also for the increased proportion of primary BA in the total plasma BA pool. It cannot be excluded that BA (when bound to colesevelam) are better protected against the metabolism by intestinal microbiota or that colesevelam per se affects the composition and metabolism of intestinal microbiota resulting in the suppression of CA transformation.

Changes to the BA profile in plasma may have a pronounced impact on BA signaling in the systemic circulation. Some of the positive effects of colesevelam are assumed to be caused by the interaction of BA with the FXR and TGR5 receptors. However, hydrophilic CA is a weaker ligand for these receptors (Wang et al. 1999, Sato et al. 2008), so it may be then expected that the more hydrophilic BA profile may diminish the activation of these receptors in circulation.

Despite the comprehensively described effect of colesevelam treatment on glycemic control, we did not observe any significant effect of colesevelam therapy on insulin, total and active GLP-1 concentrations or HOMA-IR in our healthy men. In our study, we noted only a transient decrease in glycemia. These findings are in relatively close agreement with observations that HOMA-IR improves after treatment with colesevelam in diabetics only, and not in healthy controls (Brufau et al. 2010). Therefore, it cannot be excluded that the positive effect of BA sequestrant therapy on glucoregulation may be seen only in subjects who are insulin-resistant, not in healthy subjects with normal insulin sensitivity.

Similar to the effect of the treatment on glycemic control, only transient and modest changes were observed in levels of TSH and T3 concentrations. It has been shown that BA activate a cyclic-AMP-dependent thyroid hormone, which in turn activates type 2 iodothyronine deiodinase - an enzyme responsible for the conversion of T4 to T3 - through activation of the TGR5-signaling pathway (Watanabe et al. 2006). However, such an effect is unlikely after colesevelam treatment, since hydrophilic CA binds to TGR5 with a lower affinity than CDCA and DCA, which are more hydrophobic (Sato et al. 2008).

We are aware that there are some limitations to our study - the sample size was small and the method used to evaluate BA concentrations did not allow us to discriminate between conjugated and unconjugated BA. Moreover, the concentrations of BA in fasting plasma may not have corresponded to the changes in BA 
concentrations in portal circulation. In addition, the study was carried out in healthy subjects and it cannot be excluded that the results in patients that are insulinresistant may be different.

Based on our pilot study, it can be concluded that the $-203 \mathrm{~A} / \mathrm{C}$ polymorphism of the CYP7A1 gene does not affect the response of cholesterolemia and/or BA synthesis to colesevelam treatment, at least in healthy subjects. Importantly, we document that CYP7A1 activity is downregulated immediately after initiation of therapy. Although the treatment does not affect plasma BA concentration, it results in pronounced changes in their spectrum, characterized by an increase in hydrophilic CA. On the other hand, it does not appear that BA sequestrant treatment has any significant effects on parameters related to glycemic control and thyroidal function in healthy, insulin-sensitive subjects.

\section{Conflict of Interest}

There is no conflict of interest.

\section{Acknowledgements}

The project was supported by grant No. NT13151-4/2012 from IGA MH CR.

\section{References}

AXELSON M, BJORKHEM I, REIHNER E, EINARSSON K: The plasma level of 7 alpha-hydroxy-4-cholesten-3-one reflects the activity of hepatic cholesterol 7 alpha-hydroxylase in man. FEBS Lett 284: 216-218, 1991.

BRUFAU G, STELLAARD F, PRADO K, BLOKS VW, JONKERS E, BOVERHOF R, KUIPERS F, MURPHY EJ: Improved glycemic control with colesevelam treatment in patients with type 2 diabetes is not directly associated with changes in bile acid metabolism. Hepatology 52: 1455-1464, 2010.

CHIANG JY: Bile acids: regulation of synthesis. J Lipid Res 50: 1955-1966, 2009.

CHIANG JY: Bile acid metabolism and signaling. Compr Physiol 3: 1191-1212, 2013.

COUTURE P, LAMARCHE B: Ezetimibe and bile acid sequestrants: impact on lipoprotein metabolism and beyond. Curr Opin Lipidol 24: 227-232, 2013.

COUTURE P, OTVOS JD, CUPPLES LA, WILSON PW, SCHAEFER EJ, ORDOVAS JM: Association of the A-204C polymorphism in the cholesterol 7alpha-hydroxylase gene with variations in plasma low density lipoprotein cholesterol levels in the Framingham Offspring Study. J Lipid Res 40: 1883-1889, 1999.

GOODWIN B, JONES SA, PRICE RR, WATSON MA, MCKEE DD, MOORE LB, GALARDI C, WILSON JG, LEWIS MC, ROTH ME, MALONEY PR, WILLSON TM, KLIEWER SA: A regulatory cascade of the nuclear receptors FXR, SHP-1, and LRH-1 represses bile acid biosynthesis. Mol Cell 6: 517-526, 2000.

HALUZIKOVA D, LACINOVA Z, KAVALKOVA P, DRAPALOVA J, KRIZOVA J, BARTLOVA M, MRAZ M, PETR T, VITEK L, KASALICKY M, HALUZIK M: Laparoscopic sleeve gastrectomy differentially affects serum concentrations of FGF-19 and FGF-21 in morbidly obese subjects. Obesity (Silver Spring) 21: 13351342, 2013.

HOFMAN MK, WEGGEMANS RM, ZOCK PL, SCHOUTEN EG, KATAN MB, PRINCEN HM: CYP7A1 A-278C polymorphism affects the response of plasma lipids after dietary cholesterol or cafestol interventions in humans. J Nutr 134: 2200-2204, 2004.

HUBACEK JA, PITHA J, SKODOVA Z, POLEDNE R, LANSKA V, WATERWORTH DM, HUMPHRIES SE, TALMUD PJ: Polymorphisms in CYP-7A1, not APOE, influence the change in plasma lipids in response to population dietary change in an 8 year follow-up; results from the Czech MONICA study. Clin Biochem 36: 263-267, 2003.

INSULL W JR: Clinical utility of bile acid sequestrants in the treatment of dyslipidemia: a scientific review. South Med J 99: 257-273, 2006.

KAJINAMI K, BROUSSEAU ME, ORDOVAS JM, SCHAEFER EJ: Interactions between common genetic polymorphisms in ABCG5/G8 and CYP7A1 on LDL cholesterol-lowering response to atorvastatin. Atherosclerosis 175: 287-293, 2004.

KAJINAMI K, BROUSSEAU ME, ORDOVAS JM, SCHAEFER EJ: A promoter polymorphism in cholesterol 7alphahydroxylase interacts with apolipoprotein $\mathrm{E}$ genotype in the LDL-lowering response to atorvastatin. Atherosclerosis 180: 407-415, 2005. 
KOVAR J, SUCHANEK P, HUBACEK JA, POLEDNE R: The A-204C polymorphism in the cholesterol 7alphahydroxylase (CYP7A1) gene determines the cholesterolemia responsiveness to a high-fat diet. Physiol Res $\mathbf{5 3}$ : 565-568, 2004.

LENICEK M, JUKLOVA M, ZELENKA J, KOVAR J, LUKAS M, BORTLIK M, VITEK L: Improved HPLC analysis of serum 7alpha-hydroxycholest-4-en-3-one, a marker of bile acid malabsorption. Clin Chem 54: 1087-1088, 2008a.

LENICEK M, KOMAREK V, ZIMOLOVA M, KOVAR J, JIRSA M, LUKAS M, VITEK L: CYP7A1 promoter polymorphism $-203 \mathrm{~A}>\mathrm{C}$ affects bile salt synthesis rate in patients after ileal resection. J Lipid Res 49: 26642667, 2008b.

LRC-CPPT - Lipid Research Clinics Coronary Primary Prevention Trial Results: I. Reduction in incidence of coronary heart disease. JAMA 251: 351-364, 1984a.

LRC-CPPT - Lipid Research Clinics Coronary Primary Prevention Trial Results: II. The relationship of reduction in incidence of coronary heart disease to cholesterol lowering. JAMA 251: 365-374, 1984b.

LIU J, LU H, LU YF, LEI X, CUI JY, ELLIS E, STROM SC, KLAASSEN CD: Potency of individual bile acids to regulate bile acid synthesis and transport genes in primary human hepatocyte cultures. Toxicol Sci 141: 538-546, 2014.

MATTHEWS DR, HOSKER JP, RUDENSKI AS, NAYLOR BA, TREACHER DF, TURNER RC: Homeostasis model assessment: insulin resistance and beta-cell function from fasting plasma glucose and insulin concentrations in man. Diabetologia 28: 412-419, 1985.

OCKENGA J, VALENTINI L, SCHUETZ T, WOHLGEMUTH F, GLAESER S, OMAR A, KASIM E, DUPLESSIS D, FEATHERSTONE K, DAVIS JR, TIETGE UJ, KROENCKE T, BIEBERMANN H, KOHRLE J, BRABANT G: Plasma bile acids are associated with energy expenditure and thyroid function in humans. J Clin Endocrinol Metab 97: 535-542, 2012.

SATO H, MACCHIARULO A, THOMAS C, GIOIELLO A, UNE M, HOFMANN AF, SALADIN R, SCHOONJANS K, PELLICCIARI R, AUWERX J: Novel potent and selective bile acid derivatives as TGR5 agonists: biological screening, structure-activity relationships, and molecular modeling studies. J Med Chem 51: 18311841, 2008.

SAUTER G, BERR F, BEUERS U, FISCHER S, PAUMGARTNER G: Serum concentrations of 7alpha-hydroxy-4cholesten-3-one reflect bile acid synthesis in humans. Hepatology 24: 123-126, 1996.

SETCHELL KDR, LAWSON AM: Bile acids. In: Mass Spectrometry. LAWSON AM (ed.), Walter de Gruyter, Berlin and New York, 1989, pp 53-125.

VÍTEK L, HALUZÍK M: The role of bile acids in metabolic regulation. J Endocrinol 228: R85-R96, 2016.

VÍTEK L, NOVOTNÝ L, ŽÁK A, STAŇKOVÁ B, ZIMA T, POLITO A, CESARE G, ZERBINATI C, IULIANO L: Relationship between serum bilirubin and uric acid to oxidative stress markers in Italian and Czech populations. J Appl Biomed 11: 209-221, 2013.

WANG H, CHEN J, HOLLISTER K, SOWERS LC, FORMAN BM: Endogenous bile acids are ligands for the nuclear receptor FXR/BAR. Mol Cell 3: 543-553, 1999.

WANG J, FREEMAN DJ, GRUNDY SM, LEVINE DM, GUERRA R, COHEN JC: Linkage between cholesterol 7alpha-hydroxylase and high plasma low-density lipoprotein cholesterol concentrations. J Clin Invest 101: 1283-1291, 1998.

WATANABE M, HOUTEN SM, WANG L, MOSCHETTA A, MANGELSDORF DJ, HEYMAN RA, MOORE DD, AUWERX J: Bile acids lower triglyceride levels via a pathway involving FXR, SHP, and SREBP-1c. J Clin Invest 113: 1408-1418, 2004.

WATANABE M, HOUTEN SM, MATAKI C, CHRISTOFFOLETE MA, KIM BW, SATO H, MESSADDEQ N, HARNEY JW, EZAKI O, KODAMA T, SCHOONJANS K, BIANCO AC, AUWERX J: Bile acids induce energy expenditure by promoting intracellular thyroid hormone activation. Nature 439: 484-489, 2006.

ZIEVE FJ, KALIN MF, SCHWARTZ SL, JONES MR, BAILEY WL: Results of the glucose-lowering effect of WelChol study (GLOWS): a randomized, double-blind, placebo-controlled pilot study evaluating the effect of colesevelam hydrochloride on glycemic control in subjects with type 2 diabetes. Clin Ther 29: 74-83, 2007. 